\section{$\beta$-Methyl-D-Glucoside in the Leaves of Medicago sativa}

DURING the course of the isolation and identification of $x$-galacto-heptulose ${ }^{1}$ other carbohydrate compounds were isolated from an alcoholic extract of the leaves of alfalfa (Medicago sativa, var. Caliverde) by chromatographic separation. We wish to report that $\beta$-methyl-o-glucoside has been identified as one of these compounds. Although $\beta$-methyl-D-glucoside has been reported to be present in the leaves of Scabiosa succisa $a^{2}$, to our knowledge it has not been reported to occur in alfalfa.

When a syrup (about 10 per cent solids), prepared from an alcoholic extract of alfalfa leaves, was analysed qualitatively for sugars by paper chromatography, a very faint flesh-pink zone was detected by an aniline developing reagent ${ }^{3}$. This zone had an $R_{F}$ similar to that of xylose, and initially the carbohydrate responsible for this reaction with aniline was thought to be xylose. An investigation was undertaken to verify the identity of this compound, and by means of heavy paper chromatography the carbohydrate was isolated and a crystalline compound obtained.

The following procedure was used to separate the compound which afterwards was identified as $\beta$. methyl-D-glucoside. Leaves and some petioles of field-grown alfalfa were stripped from the stems directly after cutting the shoot and were placed in boiling 95 per cent ethyl alcohol. The final concentration of alcohol in the extract was adjusted to be about 80 per cent. The alcohol extract was evaporated under a stream of air on a steam bath. The syrup was cooled, transferred with water on to a Buchner funnel containing a 'Celite' mat, filtered with suction, and washed with water. The filtrate was passed through a cation (' $I R-120$ ', $\mathrm{H}^{+}$form) and an anion ('Duolite $A-4$ ', $\mathrm{OH}^{-}$form) exchange resin and then evaporated to about 10 per cent solids. About $1 \mathrm{ml}$. of this syrup was streaked on water-washed and dried Whatman $3 M M(18 \times 22$ in. $)$ paper sheets and irrigated with ethyl acetate/pyridine/water $(8: 2: 1$ $\mathrm{v} / \mathrm{v})$. After irrigation, strips from the sheets were developed with the aniline reagent; the band corresponding to the pink area previously noted was identified, cut from the sheet, and eluted with water. The eluate was passed through the ion-exchange resins and evaporated to a syrup and, upon standing, the syrup became filled with a crystalline material. The crystals were recrystallized from 95 per cent ethyl alcohol, filtered, washed with anhydrous diethyl ether, and air dried.

The isolated crystalline compound did not show a copper-reducing value; a 5 per cent solution gave a faint chromatographic test with aniline and a positive test with silver nitrate reagent ${ }^{4}$. However, after hydrolysis in $3 \mathrm{~N}$ hydrochloric acid at $80^{\circ} \mathrm{C}$., a positive chromatographic test for glucose was found and a reducing value of 95 per cent (calculated as glucose) was determined by the Somogyi micro-copper methods ${ }^{5}$. Glucose oxidase (DeeO-Takamine Laboratory, Clifton, New Jersey) completely oxidized the glucose produced by acid hydrolysis. This confirmed the presence of glucose. The D-configuration for glucose was also established, as $\mathrm{x}$-glucose was not oxidized by glucose oxidase. The presence of $\mathbf{D}$-glucose in the hydrolysate, and an $R_{F}$ which was similar to those observed for other sugars containing a methyl group, suggested that the compound might be a methyl-glucoside. The crystalline compound had a melting point of $106^{\circ}-107^{\circ} \mathrm{C}$. as compared with $104^{\circ} \mathrm{C}$. reported for $\beta$-methyl-D-glucoside and $167^{\circ}-168^{\circ} \mathrm{C}$. found for $\alpha$-methyl-D-glucoside. Positive identification of the compound as $\beta$-methyl-D-glucoside was made by comparison of X-ray powder diffraction patterns and infra-red spectra of the unknown and authentic samples of $\alpha$-methyl-D-glucoside and $\beta$-methyl-D. glucoside. Identical X-ray powder diffraction patterns and infra-red spectra were obtained for the unknown and $\beta$-methyl-D-glucoside. Thus, by means of isolation and identification, the presence of $\beta$-methyl$\mathrm{D}$-glucoside in Medicago sativa was established.

The investigation was supported in part by a grant $(R G-7714)$ from the National Institutes of Health, Bethesda, Maryland.

\section{E. A. МсСомв V. V. RENDIG}

Department of Soils and Plant Nutrition, University of California,

Davis, California. ${ }^{1}$ McComb, E. A., and Rendig, V. V., Arch. Biochem. Biophys. (in

${ }^{2}$ Wattiez, L. N., J. Pharm. Belg., \%, 81 (1925).

${ }^{3}$ McCready R. M., and McComb, F. A., Anal. Chem., 26, 1645 (1954).

Trevelyan, W. E., Procter, D. P., and Harrison, J. S., Nature, 166 444 (1950). s Official and Tentative Methods of Analysis, eighth ed. (Washington,
D.C., 1955).

\section{Root Ecology of Tilia europaea L. : Anatomy of Mycorrhizal Roots}

ECTotrophIC mycorrhizæ of the conifers have been investigated by a number of workers ${ }^{1-3}$. Special mention may be made of the contributions ${ }^{4-6}$ to this problem from the anatomico-ecological aspect. Comparatively very little is known about the deciduous forest trees from this point of view ${ }^{7-9}$. Tilia americana and $T$. parvifolia have also been listed as endotrophic ${ }^{10}$ and endotrophic as well as ectotrophic ${ }^{11}$ respectively.

The root specimens of $40-60$ year-old trees and seedlings 1-3 yr. old of Tilia europaea were investigated in connexion with this problem. Specimens were sectioned and stained in combination of safranin and aniline blue. The fungus mantle in almost all cases was found undisturbed by the normal procedure of preparing permanent sections, which is contrary to the expressed view ${ }^{5}$.

The form of the root system in lime is modified to a certain extent in mature adult trees with the depth and the kind of soil in a particular locality. The root system shows heterorhizy, that is, there exists a difference into 'long' and 'short' roots, the former forming the main skeleton of the root system, and the latter most of the absorptive surface for nutrition. So far as our investigation goes the roots of lime and beech present a lot of similarity. The account presented here supports the view ${ }^{8}$ that the mycorrhizal roots are the changed form of the end-roots of limited growth: and this 'changed form' of mycorrhizæ presents a number of morphological and anatomical features. None of the long roots was found to be mycorrhizal, contrary to what has been described ${ }^{4-7}$ for some trees.

The mycorrhiza in Tilia is that of ectotrophic type, where the fungal mantle may be very thick or very thin and in some cases also forming the Hartig net, the extent of which may vary in different roots. The classification into superficial ectotrophic and ectotrophic ${ }^{7}$ for Fragus might be the stages of the same in the case of Tilia. Rhizodermis is not much 